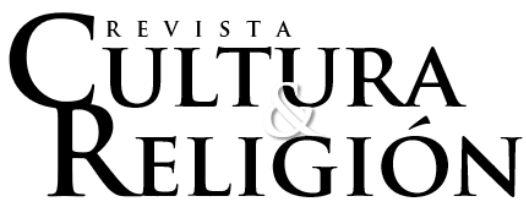

Vol. XIV, N 1 (2020) pp. 26-40

Recibido: 24 de enero, 2020

Aceptado: 1 de abril, 2020

\title{
MARTÍN LUTERO Y PREFACIO DEL CORÁN DE BIBLIANDER (1543)
}

\author{
Martin Luther and the preface to Bibliander's Koran (1543)
}

\author{
Diego Melo Carrasco* \\ Universidad Adolfo Ibáñez \\ diego.melo@uai.cl
}

\section{Resumen}

El Corán fue un texto cuya traducción en Occidente recién se desarrolló hacia el siglo XI. Bajo los auspicios de Pedro el Venerable, este lo encargó a Robert de Ketton. Es a partir de este hito que se genera una intensa polémica antimusulmana que tendrá sus picos más importantes entre los siglos XII y XIII. Hacia el siglo XVI, el reformador Martín Lutero tomará como base estas traducciones para desarrollar una, cuya finalidad es el combate del enemigo turco a partir de sus propias bases dogmáticas. En el fondo, el combate al infiel no debía ser solo un esfuerzo físico, sino también espiritual.

Palabras clave: Corán, Pedro el Venerable, Robert de Ketton, Theodoro Bibliander, Martín Lutero.

\begin{abstract}
The first translation of the Koran in the West was undertaken in the 11th century. At the bequest of Peter the Venerable, the task was given to Robert de Ketton. And it was following this major event that an intense anti-Muslim controversy was generated that would reach its peaks between the 12th and 13th centuries. Moving forward to the 16th century, the religious reformer Martin Luther used these translations to develop one in which the purpose was to combat the Ottoman enemy with their own dogmatic foundations. In the end, the struggle against the infidel was not only to involve a physical effort, but also a spiritual one.
\end{abstract}

Keywords: Koran, Peter the Venerable, Robert de Ketton, Theodore Bibliander, Martin Luther.

\footnotetext{
* Doctor en Historia, Universidad de Salamanca. Profesor titular, Departamento de Historia y Ciencias Sociales, Facultad de Artes Liberales, cátedra al-Andalus|Magreb, Universidad Adolfo Ibáñez (Santiago, Chile). https://orcid.org/0000-0001-5930-1543
} 


\section{Antecedentes: de frente al "otro", imagen y discurso}

Indicar que hacia el siglo VII d.C. vastas zonas de la denominada Europa occidental no habían sido evangelizadas, no es novedad alguna. De hecho, sabemos con certeza que los pasos dados por los primeros monjes fueron difíciles, sobre todo en aquellos ambientes donde aún existían trazas de paganismo persistente. Así es que amplios espacios de la actual Inglaterra, Sajonia, Germania, Baviera y el norte de la Península Ibérica no eran aún evangelizados para ese momento. A esto se agregaba otra situación, no menos importante: los miembros del clero no tenían una instrucción acorde a su tarea; sabían algo de gramática, literatura y ciencia, no mucho más. Tampoco la misa -la liturgia-era un fenómeno corriente, todo lo cual hacía que los fieles tuvieran una idea muy vaga de los aspectos de la doctrina cristiana (Sénac, 2011). Por tanto, no era de extrañar que en su vida religiosa cotidiana coexistieran -fundidas- prácticas y tradiciones ligadas a una superchería milenaria, junto con cuestiones propias de la doctrina cristiana: un sincretismo. Sobre ese rescoldo se asentó el cristianismo, pero a la vez, esta misma situación ayudó a que no se extendiera ningún conocimiento del mundo musulmán (Sénac, 2011). Lo anterior es importante y fundamental a la hora de comprender que cuando el islam cruza el estrecho de Gibraltar, el llamado "Occidente cristiano" no era más que una realidad teórica, casi ficticia (Sénac, 2011), con amplios claros paganos en el bosque.

Todo esto llamaba de forma urgente a la consolidación del mensaje cristiano, lo cual suponía un gran esfuerzo por parte de la Iglesia. Para lograr estos objetivos era fundamental la fijación de ciertos elementos que permitieran la estabilización doctrinal junto con una preparación más profunda del clero. (De la Cruz, 2004; Petrus, 2004). Sin embargo, ya consolidados estos aspectos, el foco de la preocupación cambió y ya en el siglo X los cluniacenses comenzaron una investigación más profunda de la religión musulmana. Con todo, ese esfuerzo inicial no bastaba y en el siglo XII aún no existía una idea pormenorizada de lo que era el islam, es decir, se manifestaba una confusión, persistente en muchos sentidos, que gravitaba entre la idea de herejía y religión. De hecho, Gilberto de Nogent (1055-1124), al inicio de su crónica Gesta dei per Francos (Luchitskaja, 2000), nos presenta una biografía sucinta y básica de Mahoma a partir de lo que el "pueblo" dice de él (Petrus, 2004; Gomes, 2005). Muy burlona, y en el estilo de Teófanes (758-818), nos habla de Mahoma como un villano pintoresco, embaucador, heresiarca, sinvergüenza, cuyos acólitos proporcionan un enemigo adecuado para los caballeros francos (Tolan, 2007; Cecota, 2012; Kaegi, 1969; Luchitskaja, 2000). En el mismo tenor se inscriben las biografías posteriores de Embrico de Mainz, Vita Mahumeti (Luchitskaja, 2000, Tolan, 1996); la de Gautier de Compiègne, De otia Machometi (Huygens, 1956; Cambier, 1958; Luchitskaja, 2000) y la Vita Machometi de Adelfo (Tolan, 2007; González Muñoz, 2015).

Con el paso del tiempo, la investigación en torno a la figura de Mahoma fue desarrollando un mayor interés entre los cristianos, quienes comenzaron a aprender sobre las complejidades de la doctrina del islam y, al mismo tiempo, considerarlo una amenaza espiritual, con lo cual se hacía necesario establecer una respuesta sistemática contra él en términos teológicos cristianos. Esto significaba pensar que si bien el "otro" estaba en un error, era posible de ser corregido (Schwoebel, 1965). Para lograr lo anterior, era necesario profundizar en los aspectos principales del islam, ingresando de lleno en sus cuestiones doctrinales más importantes. Al respecto, De la Cruz establece que: 
El argumento en contra del Islam que consiste en poner en duda la veracidad del Corán por medio de las críticas sobre su estilo comienza a aparecer cuando el conocimiento sobre el islam aumentó gracias a los contactos directos, especialmente a partir de la segunda cruzada y, sobre todo, gracias a los estudios elaborados por los misioneros durante la preparación y el desarrollo de la experiencia del contacto directo con el mundo islámico, es decir a mediados del siglo XIII. (De la Cruz, 2004, p. 1)

Esto, por tanto, suponía obligadamente realizar una traducción del Corán para poder ingresar en las bases y complejidades doctrinales que suponía esta religión. Es en ese contexto cuando el abad de Cluny, Pedro el Venerable (1092-1156), financió a un grupo de traductores especializados (Abattouy, Renn y Weinig, 2001) -entre los que destacaba el inglés Robert de Ketton (1136-1157) - para que realizaran la traducción del texto al latín, tarea que finalizaron en 1143 (Cardini, 2002), siendo esta, a su vez, la primera traducción completa a otra lengua (Tolan, 2007).

La pregunta que salta inmediatamente es: ¿por qué Pedro el Venerable querría traducir el Corán? Pues bien, la respuesta, basada en a la evidencia histórica, es que habiendo viajado a la península ibérica (Bishko, 1956) para realizar una inspección de los monasterios cluniacenses nacidos a medida que avanzaba la "reconquista", tomó conciencia de que para combatir a los musulmanes había que hacerlo desde el plano intelectual (Bobzin, 1993); esto es, conociendo su doctrina (Le Goff, 2009; De la Cruz, 2006; Martínez Gázquez y Petrus, 2008). Sin embargo, lograr esto no fue fácil: los traductores estaban acostumbrados a traducir obras científicas y, por lo tanto, tuvieron que abandonar su trabajo y abocarse a la traducción de estos otros textos que para ellos tenían poco interés. Es por lo mismo que el mismo Pedro declaró haber desembolsado una cifra no menor de dinero (Martínez Gázquez, 2005).

Pedro el Venerable lee el Corán haciendo anotaciones que dan cuenta del carácter “insano", "impío", "ridículo", "estúpido", "supersticioso", "lascivo" y "blasfemo" del texto; en el fondo, trata de presentar la idea de que el demonio trabaja detrás y por medio de Mahoma (Tolan, 2007; Martínez Gázquez, 2005; Kritzeck, 2015), quien es descrito como un árabe pobre, vil e inculto que alcanza riqueza y poder mediante el derramamiento de sangre, el robo y la intriga (Tolan, 2007). La información que quería obtener Pedro el Venerable pretendía estar bien documentada, en oposición a la tradición legendaria sobre el islam, especialmente evidente en las referencias al profeta Mahoma (De la Cruz, 2004).

Por la misma época, Germán (Herman) de Carintia (1100-1160) tradujo una genealogía de Mahoma y Pedro de Toledo, la Risala de al-Kindi, bajo el auspicio del mismo Pedro (Martínez Gázquez, 2015). Así entonces, lo importante es que, por primera vez, el Occidente cristiano podía contar con información esencial sobre el islam (Martínez Gázquez, 2015), lo cual permitió a Pedro el Venerable (Lexikon des Mittelalters, 2003; González Muñoz, 2005) realizar su trabajo de refutación intelectual (Martínez Gázquez, 2005) contra el islam: Contra Sectam siue haeresim Sarracenorum (Tolan, 2007; Martínez Gázquez, 2005; Petrus, 2004; Martínez Gázquez, 2015; Francisco, 2007). Años después, hizo una síntesis de estos textos en el denominado Corpus Islamolatinum (seguimos, en este sentido, la conceptualización propuesta por Martínez Gazquéz, 2012; De la Cruz, 2011b; Martínez Gázquez, 2015). Así entonces, para muchos la civilización musulmana se convertirá en un tema de estudio, en una línea de investigación.

Todos estos textos daban cuenta de dos cosas importantes: el islam, por cierto, no era una secta hereje del cristianismo (Martínez Gázquez y Petrus, 2008) y, al parecer, los 
musulmanes resultaban ser mucho más de lo que se pensaba, en términos culturales (Cardini, 2002) y teológicos. De ahí que la paulatina pero creciente influencia del Oriente musulmán en Europa fue generando el desarrollo de un gusto por lo sarraceno, como establece Jurgis Baltrusaitis, cuestión que se manifestó, por ejemplo, en la arquitectura, el arte, los tejidos, la seda, entre otros (Cardini, 2002). Con todo, no cejaba la idea de la posible conversión de los musulmanes, lo cual dio pie al desarrollo de varios discursos, en los que destacará el de Raimundo Lulio (1232-1315), quien establecía que para entender y enseñar a los musulmanes, había que hablarles en su lengua. Es así como en el Concilio de Vienne de 1312 se decretó que las lenguas orientales, como el árabe o el hebreo, debían enseñarse en adelante en Roma, París, Bolonia, Oxford y Salamanca. Sin embargo, el estudio del árabe no era considerado sinónimo de islam (Cardini, 2002). Por lo mismo, en 1325, el pontífice Gregorio XII (1326-1417) recomendó que los maestros encargados de esta tarea fueran objeto de vigilancia para que no introdujeran doctrinas funestas para la piedad (Cardini, 2002).

Hacia fines del siglo XIV, el interés por el islam irá decayendo en Occidente. Quizás porque su amenaza ya no era tal, sumido en una serie de problemas internos; la descomposición de la Ummah en poderes independientes debilitará la estructura fundamental del califato. Un atisbo del tiempo pasado, un rescoldo aún, quedará en al-Andalus, mas el Máshreq estará sumido en una compleja situación, amenazado por fuerzas externas como los mongoles y los turcos (Cardini, 2002). En relación con estos últimos, sabemos que su avance, en su primera etapa de establecimiento, fue avasallador, en parte porque no había un poder consolidado que pudiera enfrentárseles. Ciertamente, Bizancio había quedado muy debilitado luego de los acontecimientos de la Cuarta Cruzada (1204) (Cardini, 2002), todo lo cual facilitó el ingreso y la conquista, por parte de los turcos, de vastas extensiones del antiguo imperio (Ducas, 2007).

Hacia esta misma época, Nicolás de Cusa (1401-1464) estaba enfrascado en un manuscrito que contenía la versión latina del Corán de Robert de Ketton (De la Cruz, 2003). Esto le permitió elaborar la construcción de una cruzada que difundiese entre los cristianos una idea más exacta y clara de las insensateces y contradicciones que caracterizaban al Corán (Cardini, 2002). Para conseguir sus propósitos, recurrió al místico Dionisio de Ryjkel (14021471) (Sandoval Martínez, 2006; Schwoebel, 1965), más conocido como Dionisio el Cartujano, a quien debemos el tratado, en forma de diálogo, Contra Alchoranum et sectam Machometicam (1533), en el que tachaba o silenciaba sistemáticamente aquellos fragmentos en los que la proximidad entre islam y cristianismo era evidente (Cardini, 2002; Sandoval Martínez, 2006). Para la elaboración del mismo, se sirvió de la Collectio Islamocristiana (Sandoval Martínez, 2006). El material recopilado sirvió a Cusa para redactar otro tratado, la Cribratio Alchorani (Tolan, 2010; Sanz Santacruz, 2007; Schwoebel, 1965), especialmente destinado para aquellos que deseasen convertir a los musulmanes (Cardini, 2002; Sanz Santacruz, 2007). Por tanto, a partir de lo anterior, ya se manifestaba, con creces, aquel género que sería esencial en ese momento: la polémica antimusulmana.

\section{El emperador frente a la amenaza: los turcos en el horizonte}

Cuando Carlos V (1500-1558) iniciaba su reinado, tenía frente a él al poderoso Solimán el Magnífico (1494-1566) (Carabias, 2009), quien no ocultaba, bajo ningún pretexto, sus pretensiones expansionistas sobre la Europa cristiana. Una de las misiones del emperador del Sacro Imperio era no solo la defensa de la cristiandad, sino que, en la medida de lo posible, liderar una cruzada que incluía Tierra Santa, Constantinopla y Grecia. Sin 
embargo, aunque quisiera tomar las riendas del asunto, diferentes cuestiones fueron haciendo que el accionar de Carlos se fuera posponiendo: el mismo año que Solimán se apoderaba de Belgrado (1521) (Forell, 1945), Carlos tuvo que lidiar con la rebelión comunera de Castilla, además de la rivalidad con Francisco I (1494-1547), que se manifestó en las guerras hispanofrancas y la aparición de Lutero en el horizonte, a quién convocó a la Dieta Imperial de Worms (1521). Una vez superados estos problemas, nada parecía impedir que Carlos iniciase su cruzada contra los turcos.

Fue así como en 1532 Carlos V se encontraba al pie del cañón esperando la llegada de Solimán el Magnífico, quien hacía grandes preparativos para la ofensiva sobre Viena, como venganza del malogrado intento de 1529 (Francisco, 2007). El emperador montaba así un variopinto ejército de diversas naciones, costumbres y lenguas, pero con el mismo objetivo: combatir al turco. Los vieneses, por su parte, se sentían bastante más confiados, debido al cerco anterior, a lo que se sumaba el apoyo de ejércitos venidos desde España, Italia y Alemania. Lo anterior conminó al debilitado ejército de Solimán a retirarse de la campaña.

\section{Mismo tiempo: lo coetáneo y lo amenazante}

En el siglo XVI había dos elementos que, en relación con el mundo islámico, tenían una importancia capital: por una parte, la idea de una amenaza ideológica: el combate al infiel por medio de las ideas; por otra, la presencia de los turcos, quienes estaban al acecho de la cristiandad. No profesaban una herejía, sino una religión distinta. En otro plano, la amenaza real: avanzaban, y no lento, sobre los territorios de la Europa oriental, asomándose paulatinamente sobre Occidente. De este modo, ejercían una presión en todos los frentes. ¿Cómo frenarlos?, ¿cómo combatirlos? Ya hemos visto los intentos de Carlos V, no obstante, en el plano de las ideas, ¿cómo se podía luchar contra ellos? Se renovaba el espíritu de la polémica antimusulmana, pero con un signo distinto, porque estará bajo el amparo de un reformador.

Martín Lutero (1483-1546) provenía de una familia de origen campesino. Su padre había ascendido en la explotación de las minas de Mansfeld: de un simple minero a pequeño empresario. Por lo mismo, él quería que su hijo estudiara Derecho, pero en 1505, luego de terminar los estudios preparatorios en la Facultad de Artes de la Universidad de Erfurt, Martín optó por entrar al monasterio de los eremitas agustinos, ordenándose sacerdote en 1507.

En el documento conocido como Las 95 tesis, Lutero atacaba la práctica eclesiástica de la "indulgencia" (Ramírez, 2014). Aunque esta había sido practicada por la Iglesia desde la temprana Edad Media, en su forma original no era más que la conmutación de una pequeña parte de la penitencia a causa de la donación de una suma de dinero para fines religiosos. Tal donación, en ningún caso podía ser vista como un mérito suficiente para el perdón de los pecados, pues ello exigía, además de la penitencia, la confesión ante un sacerdote, el arrepentimiento sincero y la absolución (Suárez, 2003). Con el tiempo, las indulgencias se transformaron en una vía ventajosa para poder financiar todas las tareas que le correspondían a la Iglesia, llegando, en tiempos de Lutero, a ser francamente escandalosas. Paulatinamente se comenzaron a vender indulgencias válidas para pecados futuros, convirtiéndose en un negocio lucrativo, tanto así que hasta los banqueros europeos terminaron encargándose de su manejo (Suárez, 2003).

Bastante estudiados han sido los fundamentos de su movimiento reformista, su crítica al comportamiento de la jerarquía de la Iglesia y especialmente al papa, todo lo cual se manifiestó en un mensaje apocalíptico de desenmascaramiento: el papa de Roma es el 
Anticristo (Lutz, 2009). Esto se basaba en la idea de que la Iglesia tenía una concepción totalmente errada del papel que le correspondía en el mundo. Es más, en su opinión, el "Vicario de Cristo" estaba más preocupado de los asuntos terrenales que de los espirituales (Suárez, 2003; Ramírez, 2014).

Por otra parte, el reformador iba desarrollando la siguiente idea en torno a la política: el pontífice no es ninguna autoridad a la que se deba obediencia, sino más bien, un ser dañino para la comunidad. Eliminando el orden jerárquico de la Iglesia católica, los cargos eclesiásticos no son autoridad. Todo esto ayudaba al desarrollo de un juicio de síntesis por parte de Lutero: tanto el papa como los turcos son la encarnación del Anticristo (Valero Cuadra, 2000; Lutero, 1529; Forell, 1945; Jerkins, 2012; Marshall, 2012).

Según el reformador, los turcos constituían un peligro, ante lo cual establecía: "Cuando señalé que no se debía subestimar el poder del turco, se tildó mi afirmación de palabras necias y vacías; pues supuestamente había muchos príncipes poderosos" (Lutero, 1529, p. 3) y, por tanto, en ese sentido, su fe merecía su más absoluto desprecio (Cardini, 2002). Dicho esto, la amenaza real otomana debía ser conocida, medida e integrada. Lutero había tenido acceso a la edición del Corán de Robert de Ketton, en 1542. Sin embargo, ya trece años antes, había manifestado su deseo de traducir al alemán algunos extractos coránicos que habían llegado a sus manos, pero en lugar de ello tradujo un libro de polémica antimusulmana, la Confutatio de Ricoldo (Valero Cuadra, 2000; Jerkins, 2012; Simon, 1931; Francisco, 2007). Lutero creía en el fin del mundo y la amenaza turca sería una señal de ello, por eso para él era fundamental reconocer al último enemigo, que actuaba tanto fuera como dentro de la Iglesia (Valero Cuadra, 2000; Francisco, 2007). En este sentido, el enemigo externo estaría representado por los turcos otomanos (Buchanan, 1956) y el interno, más complejo de visualizar, por el papado (Valero Cuadra, 2000).

El paralelismo entre el Corán como la "ley" de los turcos y la ley de la Iglesia de Roma representada por sus indulgencias continuaba en la primera "confrontación" de Lutero con el Corán, que encontramos en su primer escrito sobre los turcos, de 1529 (Clark, 1984; Forell, 1945; Simon, 1931), en el que establecía:

En cambio el papa, precisamente porque no pretende ser un enemigo ni turco, sino el amado padre, en efecto, el santísimo padre y fidelísimo pastor, pues él aparta de Cristo a las nobles almas con su execrable doctrina humana y las conduce a la justicia propia, que es la verdadera muerte espiritual, equivaliendo a la doctrina blasfema de Mahoma o los turcos: [...] En suma, dondequiera que vayamos está presente el verdadero patrón, el diablo. Si caemos en manos del turco, vamos al diablo; si permanecemos bajo el papa, caeremos en el infierno. Hay puros diablos en ambas partes y por todos lados [...] (Lutero, 1529, p. 20)

\section{Lutero y el Corán}

Lutero se plantea como acérrimo enemigo de la fe turca, sobre todo después del sitio de Viena de 1529 (Francisco, 2007; Buchanan, 1956), toda vez que este enemigo externo coexiste con el otro interno. Paulatinamente, el reformador va dando forma a su teoría con respecto a los turcos y el estudio de su fe (Buchanan, 1956; Levin, 2011). En ese sentido, hemos afirmado que Lutero leyó el Corán de Ketton en 1542, sin embargo, la investigación reciente da cuenta de que no lo conocía en su magnitud y totalidad, sino más bien, parcelado, por extractos de obras que había leído, todas pertenecientes al género ligado a la polémica 
antimusulmana, como la Confutatio de Ricoldo (1243-1320) (Francisco, 2007), la Cribatio Alcoranis de Nicolás de Cusa (1401-1464) (Martínez Gázquez, 2015; Francisco, 2007); el desconocido tratado llamado Libellus (Miller, 2013; Wolf, 1941; Francisco, 2007). Finalmente, también el Corán Latino, que él catalogaba de mala traducción (Valero Cuadra, 2000). Así entonces, a partir de estos textos Lutero comenzó a interesarse en los principios básicos de la teología del Corán, notando que su mensaje tenía connotaciones tanto teológicas como políticas. Todo esto le llevó a concluir que los musulmanes eran destructores, enemigos y blasfemos respect de Jesucristo (Francisco, 2007). Estas apreciaciones fueron tomando una forma determinada que las llegó a expresar en su escrito "Alegato contra los turcos" (1529), en el que claramente establece que los cristianos deben luchar contra los musulmanes (Francisco, 2007). Sin embargo, su intento fue más allá, al indicar la importancia que tenía el poder contar con una traducción confiable del Corán y al alcance de los cristianos, para que pudiera ser leída con sus propios ojos (Francisco, 2007; Clark, 1984). En definitiva, lo que proponía no era un combate físico, sino en el plano de las ideas.

Si bien Robert de Ketton había dado un paso importante, no era suficiente, entonces: ¿hasta dónde era posible reconocer el verdadero alcance del estudio del Corán? O, dicho de otro modo, ¿qué difusión alcanzaban estos escritos? ¿Estaban destinados solo para una élite?, pues parece haber sido así: tanto las traducciones, como el discurso establecido a partir de la polémica antimusulmana, giraban en torno a grupos minoritarios. Es decir, pareciera ser que el Corán de Ketton no tuvo una amplia difusión, salvo en medios eruditos ligados al clero.

La importancia de la decisión de Lutero estribaba en el hecho de que, por primera vez, se imprimiría en Occidente el Corán en forma íntegra (Miller, 2013), tomando como texto la traducción de Robert de Ketton (Levin, 2011). De hecho, en el año 1542, recomendó al consejo de Basilea la publicación de la traducción realizada por Theodoro Bibliander (1509-1564) (Bobzin, 1993; Clark, 1984; Levin, 2011, Francisco, 2007), la que lo había dejado muy impresionado (Simon, 1931; De la Cruz, 2004; Petrus, 2004). No veía ningún peligro evidente en la traducción del texto, pues era de la idea de que ningún hombre podía cambiar su fe por el hecho de leer el Corán (Simon, 1931). Por lo mismo, y para hacer más patente este punto, se preocupó de integrar una serie de textos que, él pensaba, ilustraban de mejor manera su objetivo. Entre estos escritos estaban: Confutatio legis latae Saracenis à maledicto Mahometo (Refutación de la ley promulgada por la maldición de los sarracenos, Mahoma) por Ricoldo da Montecroce (circa 1243-1320), con una traducción al griego en paralelo (Bobzin, 1993; Levin, 2011); Historiae de Saracenorum sive Turcarum origine, moribus, nequitia, religione, rebus gestis (La historia del origen sarraceno o turco, el comportamiento, la maldad, la religión y la historia), con prefacio de Lutero; y el original griego y la traducción al latín de Contra Mahometicam fidem Christiana \& orthodoxa assertion (Contra el islam y una afirmación de la fe cristiana ortodoxa) de Juan VI Cantacuzeno, emperador de Oriente (1292-1383), además de un prefacio escrito en latín de su puño y letra en 1453, del que ahora presentamos su traducción. Por intermedio de estos, Lutero quería que los cristianos se informaran sobre el islam para que pudieran refutar sus posiciones teológicas (Bobzin, 1993) para "la propagación de la fe cristiana y de la Santa Madre Iglesia" (Clark, 1984; Jerkins, 2012). Esta publicación le granjeó, finalmente, la censura de críticos que sostenían que la impresión del Corán, aun con fines polémicos, era un peligroso reconocimiento de su importancia religiosa. 


\section{Lutero y su prefacio al Corán}

El punto central en la decisión de Lutero con respecto a la difusión del texto coránico tiene que ver, esencialmente, con poder conocer, de primera mano, la doctrina que profesaban los turcos y, de esta forma, generar conciencia en relación al peligro que realmente revestían para Europa. Para dar cuenta de lo anterior, el reformador elaboró un prefacio que ahora pasamos a comentar.

Comienza su prefacio indicando el valor y la importancia que ha tenido, a lo largo de la historia, la publicación de "folletos" sobre las costumbres de los judíos, con el objeto de refutar sus errores.

Por muchos, han sido publicados pequeños folletos que contienen los ritos, creencias y costumbres de los judíos de estos días con el propósito de refutar más fácilmente sus mentiras manifiestas y los errores y desvaríos expuestos. No hay duda de que, cuando las mentes piadosas traen el testimonio de los profetas sobre los engaños y las blasfemias de esa gente, se ven muy confirmadas en la fe y en el amor por la verdad del Evangelio y se encienden con un justo odio hacia la perversidad de las cosas de los judíos. (Melo, 2019, p. 145)

Hace referencias especialmente a Nicolás de Lira, nacido en una familia judía, pero convertido al catolicismo, quien durante cuarenta años estudió la Biblia, desarrollando una crítica textual de la misma, la cual se hace patente en su obra más importante Postillae perpetuae in universam S. Scripturam, vasta recopilación de notas y comentarios escrita entre 1322 y 1331. Este es conocido, además, por ser el primer comentario bíblico que se imprimió en 1471 (Roma). También, y en este mismo sentido, se refiere a Salomón Levy de Burgos, más conocido como Pablo de Santa María, o el Burguense, judío converso y consejero de Enrique III, cuya obra más importante fue el Scrutiniun scripturarum. En ella se expone, de forma dialogada, los errores de los judíos, rebatiéndolos, y luego explica los misterios de la fe cristiana. Finalmente, hace mención a Antonius Margaritha, converso judío -luego converso al protestantismo- que vivió durante el siglo XVI y del cual se cree fue la fuente por medio de la cual Lutero conoció el judaísmo.

En efecto, que cualquiera que sea sano o moderado considere cuánto de las calumnia más estúpida, cuánta locura y maldad hay en las creencias de los judíos, cosa que se reconoce en el hecho de que sus hombres eruditos y buenos (como Nicolas de Lyra, Salomo Levi Burgos, Margaritha) promuevan los misterios eleusinos. (Melo, 2019, p. 145)

Sin embargo, no será la única vez que Lutero se referirá a este tema, de hecho en el mismo año (1543) escribió "Sobre los judíos y sus mentiras", texto en el que afirma:

Ya me había convencido de no escribir más sobre los judíos o en contra de ellos. Pero desde que me enteré de que aquellos miserables y malditos no cesan de ser un engaño para ellos mismos y para nosotros los cristianos. Yo he publicado este pequeño libro para que yo pueda ser encontrado entre aquellos que se oponen a las actividades ponzoñosas de los judíos y como alguien que advierte a los cristianos para que no baje la guardia contra ellos. (Friedman, 1971, p. 7) 
En ese sentido, su labor misional y discursiva se construye desde la difusión y crítica de la fe del otro, en este caso infiel y blasfema. La misma metodología es la que justifica la traducción del Corán (Simon, 1931, Wolf, 1941).

Continúa Lutero estableciendo que en distintas épocas de la historia el diablo ha tenido un papel fundamental en el desarrollo de cultos que incorporaron sacrificios humanos o la adoración de animales,

[p]ues así como primero, en el paraíso, el Diablo separó de Dios a la pobre Eva, enloquecida por sus mentiras, del mismo modo es cierto que, luego de esto, han sido despertados por el Diablo las fechorías de todos los pueblos contra la verdadera enseñanza de Dios. Porque todos los pueblos sacrificaron víctimas humanas, como lo destacan no sólo los ejemplos de los antiguos romanos y griegos, sino también de algunos más recientes, como el emperador Severo; porque los egipcios adoraron a los gatos, el pueblo de Arabia a los perros, los lámpsacenianos a Priapo, y otros pueblos, a un monstruo u otro; porque degeneraciones en Chipre o en Tebas se convirtieron en ritos sagrados en Egipto o en algún otro lugar. (Melo, 2019, p. 146)

Todo esto para mostrarse enemigo de Dios y engañar la débil naturaleza humana, que sucumbe ante la tentación y el error. Asimismo, el demonio es el que ha generado los desvaríos de los judíos, negando a Cristo e inventando versiones engañosas de él, creando, además, falsas esperanzas en relación con su dominio del mundo, cuestión que no sucederá, porque no escucharon los testimonios de los profetas.

De seguro que todas estas cosas han ocurrido a causa del Diablo que impulsa las ciegas mentes humanas, en primer lugar, para mostrarse como enemigo de Dios y, en segundo lugar, para despreciar con arrogancia la débil naturaleza de la humanidad. Así, por el Diablo, también se originaron los desvaríos de los judíos cuando, después de la resurrección de Cristo, fomentaron revoluciones, cuando la ciudad de Jerusalén destruida, incitaron a la guerra bajo la dirección de Bar Kochba, y cuando, en el tiempo de Juliano, comenzaron a construir el templo de nuevo. No es menor la infamia por el hecho de que, como no son capaces de tomar las armas, descansan en sus sacrificios y maldicen al Hijo de Dios e inventan engañosas y venenosas interpretaciones corruptas del testimonio profético; elaboran ritos crueles, laceran sus propios cuerpos y los de sus hijos, y continúan teniendo cierto tipo de sueños esperanzados de dominio sobre el mundo contra los testimonios explícitos de los profetas. (Melo, 2019, p. 146)

Por tanto, el llamado del reformador es a denunciar a todos aquellos que, indistintamente, hacen la guerra contra el Evangelio: judíos, turcos y papistas.

Pero así como los apóstoles condenaron los errores de otros pueblos, así la Iglesia de Dios debe refutar los errores de todos los enemigos del Evangelio, para que la gloria de Dios y de su Hijo Jesucristo sea celebrada contra el Diablo y sus instrumentos. Mientras el Hijo de Dios estaba colgado en la cruz, el mundo entero de la naturaleza testificó con señales nuevas y terribles de que esta muerte importaba a Dios, y amenazaba no solo a los judíos, sino al mundo entero y de todos los tiempos en la medida en que rechazara al Hijo de Dios. (Melo, 2019, p. 146); incluso si unos pocos fueron conmovidos, Dios todavía quería manifestar un claro testimonio. De este modo, aunque este mundo, en el extremo de los tiempos, esté oprimido por una 
multitud inmensa de judíos idólatras, musulmanes y papistas, emitamos la voz del Evangelio y demos testimonio de que Jesucristo crucificado y resucitado, que los apóstoles nos muestran, es verdaderamente el Hijo de Dios y Salvador, y execremos de los errores de todos los que hacen la guerra contra el Evangelio. (Melo, 2019, p. 147)

Así entonces, anuncia que, siguiendo el mismo método antes empleado -para el caso judío-, ahora se abocará a escribir acerca de las creencias "pestilentes" de Mahoma; de ahí la importancia de traducir el Corán, para instruir a las personas piadosas pero, además, para refutar su contenido, comprendiendo que allí se encuentran la locura y las artimañas del diablo.

Pero, para hacer esto, también es útil examinar los escritos mismos de Mahoma. En consecuencia, he querido considerar un texto completo del Corán. No dudo de que, mientras más personas piadosas y eruditas lean estos escritos, más los errores y el nombre Mahoma serán execrados. Porque, así como la vacuidad de los judíos se observa más fácilmente una vez que sus secretos ocultos han sido revelados, así una vez que el libro de Mahoma es puesto en evidencia y examinando a fondo en todas sus partes, todos los piadosos comprenderán más fácilmente la locura y la ponzoña del Diablo y podrán más fácilmente refutarlas. Esta es la razón que me ha motivado a desear publicar este libro. (Melo, 2019, p. 147)

Al respecto, y tal como lo dijimos con anterioridad, argumenta, frente a la desconfianza que podría generar la traducción e impresión de un texto de esta naturaleza, que este no corromperá las mentes de los cristianos, puesto que es evidente que el conocimiento de aquello que es verdad, no puede sucumbir frente a la mentira.

Dado, sin embargo, que algunos temen que esta lectura corrompa como una infección las almas débiles y las aleje de Cristo, a ellos respondo así: que, en la Iglesia de Dios, no hay nadie tan débil que no tenga esta convicción fija en su mente, tan cierto como piensa, [a saber], que tan seguro como sabe que está vivo mientras sus sentidos y las operaciones de su cuerpo sigan vigorosas, que tan seguro como sabe que es de día mientras vea el sol pasar por encima de la tierra en medio del cielo, así de cierto es que es evidentemente imposible que haya cualquier religión o doctrina acerca de la adoración o invocación de Dios que sea verdadera y rechace totalmente los escritos proféticos y apostólicos. (Melo, 2019, p. 148)

Además, no se debe olvidar que, en opinión de Lutero, la Iglesia ha sido edificada sobre el fundamento de los apóstoles y los profetas, he ahí su legitimidad y quienes lo ignoran deben ser condenados.

Una es la Iglesia eterna que comienza con Adán, a quien Dios reveló con testimonios seguros y maravillosos con la misma palabra que Dios confió a los profetas y apóstoles. Una y otra vez, Dios ordena que, en esa enseñanza, sea reconocido y que todas las demás opiniones acerca de Él sean rechazadas. A esta enseñanza se nos une Dios, así como el profeta Isaías dice claramente en el capítulo 59: "Este es mi pacto, dice el Señor: mi Espíritu está en ti, y mis palabras que he puesto en tu boca no se apartarán de tu boca o la boca de tu descendencia por la eternidad". Y Cristo dice: "Si permanecéis en mí, y mis palabras permanecen en ti; todo lo que pidáis será hecho 
por vosotros". Y Pablo dice: "la Iglesia está edificada sobre el fundamento de los apóstoles y profetas”. (Melo, 2019, p. 148)

¿Dónde observa, por tanto, el peligro Lutero? En que Mahoma está ideando una nueva creencia, en contra de profetas y apóstoles, por lo tanto esta debe ser rechazada, pues la única religión es aquella revelada desde el principio por Dios.

Mahoma reconoce, sin embargo, que está ideando una nueva creencia que disiente de los profetas y apóstoles. Por lo tanto, así como rechazas firmemente las creencias de los egipcios que adoraban a los gatos y a las de los árabes que adoraban a los perros, así detestarás la nueva creación de Mahoma, porque él mismo admite abiertamente que no adhiere a la enseñanza de los profetas y apóstoles. Si hay quienes son tan ineptos como para no tener asentada en el alma la opinión según la cual la única verdadera religión es aquella que fue, desde el principio, transmitida por Dios, con claros testimonios, a través de los profetas y apóstoles, estos también, si no leen ahora los escritos de Mahoma, pero solo oyen hablar a los turcos o los ven, ¿cómo se fortalecerán contra sus creencias? (Melo, 2019, pp. 148-149)

En este sentido, la invitación es a no dejar embaucarse por el rito y las creencias de los turcos. Esto último es muy interesante, toda vez que pareciera desconocer la idea de la continuidad de la revelación que se plantea en el mismo Corán y que forma parte del ductus propio de la religión islámica. Sin embargo, y con todo el peligro que parece significar la amenaza turca, el hecho mismo de la traducción del Corán es fuente de esperanza para que los turcos puedan ser sacados de la oscuridad, producto de la acción de los cautivos cristianos que, eventualmente instruidos, puedan dar cuenta y desarrollar una misión evangelizadora.

Finalmente, el prefacio concluye con una defensa acérrima a la Iglesia en relación con su fundación, su firmeza, su continuidad, poniendo estas características como contraparte de la formulación de Mahoma. Entendiendo que debe lucharse en todos los frentes contra el diablo: contra los papistas, los judíos, los anabaptistas y ahora contra Mahoma; por eso mismo, se deben leer los textos del enemigo para refutarlos, pero a la vez para fortalecer las almas de los fieles.

Pero, ¿qué podremos decir sobre lo ignorado? De ahí que sea de gran valor para el erudito la lectura de los escritos del enemigo para refutarlos más agudamente, para sacudirlos y destruirlos con el fin de sanar a algunos o, ciertamente, para fortalecer a los nuestros con argumentos más sólidos. (Melo, 2019, p. 150)

\section{A modo de conclusión}

Hasta el siglo XII no existía claridad en relación con la idea del islam como una religión distinta y diferente; por el contrario, parecía ser que, hasta ese momento, se incorporaba dentro del ámbito de las herejías cristológicas. No será hasta la traducción del Corán llevada a cabo por Robert de Ketton, bajo los auspicios de Pedro el Venerable, que se establecerá una conciencia clara de que los musulmanes son un credo distinto y diferente. Todo esto colaborará al desarrollo, al menos durante los siglos XII al XIV, del género conocido como la polémica antimusulmana, la cual supo de un fenómeno espejo: la denominada polémica anticristiana. 
Con todo, y como hemos comentado, estos escritos si bien tuvieron una circulación importante en ciertos círculos del clero, no permearon exitosamente a otras capas sociales y, conforme fue pasando el tiempo, su uso se fue espaciando. Sin embargo, la causa fundamental de lo anterior se relaciona con el debilitamiento del califato abasí en Oriente y, a partir de esta situación, la idea de que la amenaza islámica se había debilitado, por tanto no aparecía como un enemigo a vencer. Además, para la misma época comenzó el lento, pero exitoso despegue del Occidente premoderno.

No obstante, lo anterior, una serie de episodios condicionaron a la Europa occidental. Estos hechos se asociaron a la llegada de los turcos otomanos, quienes continuaron la obra de los abasíes, reestableciendo el dominio del islam en Medio Oriente. Sin embargo, el episodio más traumático fue aquel relacionado con la toma de Constantinopla en 1453 (Clark, 1984). De ahí en adelante, solo un paso separará a los turcos de Europa, tal como se manifestó en el saqueo a Viena de 1529. Por lo tanto, la amenaza se hará patente. Nuevamente, el islam estaba en los lindes de Europa.

Paralelamente a esto, se iniciaba el proceso de reforma. Europa era amenazada en sus límites y cuestionada por su propia espiritualidad. Rápidamente, Lutero enganchó con esta doble amenaza y preparó el camino para su combate, ya sea contra el enemigo exterior (los turcos), o el interior (el papa). En ese contexto, el reformador reutilizó los textos de la polémica antimusulmana y le dio importancia al Corán como un elemento central dentro de su plan: esto era, vencer al turco por medio de sus propios argumentos, es decir, utilizando el camino misional discursivo que ya había construido para el caso judío. De ahí, entonces, el interés por traducir el Corán, cuestión que logró realizar con el apoyo de Bibliander y en cuyo prefacio hizo una llamada a cuidarse del turco, pero además conminó al cuidado de la Iglesia y la labor evangelizadora de la misma. Con todo, y pese a que fue la primera vez que el texto coránico se imprimió en Occidente, posteriormente fue criticado por el hecho de "difundir" el islam.

\section{Referencias bibliográficas}

Abattouy, M., Renn, J. y Weinig, P. (2001). Transmission as transformation: the translation movements in the medieval east and west in a comparative perspective. Science in Context, 14, 1-12.

Arias, J. (2007). Bibliografía sobre las traducciones del Alcorán en el ámbito hispano. TRANS: Revista de Traductología, 11, 263-272.

Bishko, Ch. (1956). Peter the Venerable's Journey to Spain. Studia Anselmiana, 40, 163-175.

Bobzin, H. (1993). Latin translations of the Koran. A short overview. Der Islam, 70(2), 193206.

Buchanan, H. (1956). Luther and the turks 1519-1529. Archiv für Reformationsgeschichte, 47(1-2), 145-160.

Burman, T. E. (1998). Tafsīr and translation: traditional arabic Qur'ān exegesis and the latin Qur'āns of Robert of Ketton and Mark of Toledo. Speculum, 73(3), 703-732.

Cambier, G. (1958). Quand Gauthier de Compiègne composait les Otia de Machomete. Latomus, 17(3), 531-539.

Carabias, A. (2009). Turcos contra católicos. Barrantes Maldonado y la deformación interesada de los hechos militares. Tiempos Modernos, 19(10), 1-30.

Cardini, F. (2002). Nosotros y el Islam. Barcelona: Crítica. 
Cecota, B. (2012). Islam, the arabs and umayyad rulers according to Theophanes the Confessor's Chronography. Studia Ceranea. Journal of the Waldemar Ceran Research Centre for the History and Culture of the Mediterranean Area and SouthEast Europe, $\mathrm{N}^{\circ}$ 2, 97-111.

Clark, H. (1984). The publication of the Koran in latin: a reformation dilemma. The Sixteenth Century Journal, 15(1), 3-12.

Cordero, M y Cid, J. (eds.) (2019). Contrarreforma católica, implicancias sociales y culturales: miradas interdisciplinarias. Santiago: Editorial Cuarto Propio.

De la Cruz, O. (2003). La trascendencia de la primera traducción latina del Corán (Robert de Ketton 1142-1143). Collatio, 7, 21-28.

De la Cruz, O. (2004). La llegenda de Mahoma a l'Edadt Mitjana i al Renaixement: la compilació de Bibliander. Estudi General, N²3, 97-112.

De la Cruz, O. (2006). Los textos de la llamada Collectio Toletana, fuente de información sobre el Islam. The Journal of Medieval Latin, 17, 413-434.

De la Cruz, O. (2011a). Notas a la lectura del Liber de generatione Mahumet (trad. de Hermán de Carintia, 1142-1143). En J. Martínez Gázquez, O. de la Cruz y C. Ferrero Hernández (comps.), Estudios de latín medieval hispánico (pp. 609-625). Firenze: SISMEL.

De la Cruz, O. (2011b). Genealogías del Profeta Mahoma: evolución en la literatura latina. En C. Prieto Entrialgo (comp.), Arabes in patria Asturiensium (pp. 205-223). Oviedo: Universidad de Oviedo.

Delumeau, J. (1973). La reforma. Barcelona: Editorial Labor.

Dionisio el Cartujano (1533). Contra Alchoranum \& Sectam Machometicam. Coloniae apud Petrum Quente.

Ducas, M. (2007). Historia turco bizantina. Madrid: Editorial Antonio Machado.

Forell, G. W. (1945). Luther and the war against the turks. Church History, 14(4), 256-271.

Francisco, A. (2007). Martin Luther and Islam: A Study in Sixteenth-Century Polemics and Apologetics. Leiden: Brill.

Friedman, S. (1971). Luther and Muhammad. Patterns of Prejudice, 5(2), 6-11.

Gilberto de Nogent (ed.) (1611). Gesta Dei per Francos, Hanoviae, Typis Wechlianis, apud heredes Ioan Aubrii.

Glei, R. (ed.) (1985). Pedro el Venerable. Liber contra sectam Saracenorum, 17: Christianis interpretibus etiam Saracenum adiunxi. Christianorum interpretum nomina: Robertus Ketenensis, Armannus Dalmata, Petrus Toletanus. Saraceni Mahumetus nomen erat. Altenberge: CIS.

Gomes, J. (2005). L'Exégèse monastique au XII ${ }^{\mathrm{e}}$ siècle: tropologie, intériorité et subjectivité chez Guibert de Nogent. Bulletin du Centre d'Études Médiévales d'Auxerre (BUCEMA), 9, s.p. [Consultado el 28 de enero de 2017]. Recuperado de: http://cem.revues.org/754

González Muñoz, F. (2005). Consideraciones sobre la versión latina de las cartas de alHasimi y al Kindi. Collectanea Christiana Orientalia, 2, 43-70.

González Muñoz, F. (2015). Mahométrica. Ficciones poéticas latinas del siglo XII sobre Mahoma. Madrid: Consejo Superior de Investigaciones Científicas.

Huygens, R. (1956). Otia de Machomete. Gedicht von Walter von Compiègne. Sacris Erudiri, 8(2), 287-328.

Jerkins, J. (2012). Islam in the early modern protestant imagination. Eras, 13(12), 1-19. 
Johnson, G. (2000). Muhammad and ideology in medieval christian literature. Islam and Christian-Muslim Relations, 11(3), 333-346.

Kaegi, W. (1969). Initial byzantine reactions to the arab conquest. Church History, 38(2), 139-149.

Kritzeck, J. (2015). Peter the Venerable and Islam. Peter de Venerable and the toledan collection". New Jersey: Princeton University Press.

Le Goff, J. (2009). Los intelectuales en la Edad Media. Barcelona: Gedisa.

Levin, P. (2011). Turkey and the European Union Christian and Secular Images of Islam. Nueva York: Palgrave Macmillan.

Lexikon des Mittelalters (2003). Lexikon des Mittelalters Vol. VI, s.v. Petrus (Mauricius) Venerabilis, cols. 1985-1987. Múnich: LexMA-Verlag.

Luchitskaja, S. (2000). The image of Muhammad in latin chronography of the twelfth and thirteenth centuries. Journal of Medieval History, 26(2), 115-126.

Lutero, M. (1529). Alegato contra los turcos. [Consultado el 28 de enero de 2018]. Recuperado de: http://escriturayverdad.cl/wpcontent/uploads/ObrasdeMartinLutero/15261530/1529AlegatoContralosTurcos.pdf

Lutero, M. (1977). Charlas de sobremesa. Obras. Edición preparada por Teófanes Egido. Salamanca: Ed. Sígueme.

Lutz, H. (2009). Reforma y Contrarreforma. Madrid: Alianza Editorial.

Marshall, P. (2012). Rather with papists than with turks. Reformation, 17(1), 135-149.

Martínez Gázquez, J. (2005). El lenguaje de la violencia en el prólogo de la traducción latina del Corán impulsada por Pedro el Venerable. CEHM, 28, 243-252.

Martínez Gazquéz, J. (2012). «Islamolatina». La percepción del Islam en la Europa cristiana. Traducciones latinas del Corán. Literatura latina de controversia. Medievalia, 15, 3942.

Martínez Gázquez, J. (2015). Glossae ad Alchoran Latinum Roberti Ketenensis translatoris, fortasse a Petro Pictauiense redactae: An Edition of the Glosses to the Latin Qur'an in BNF MS Arsenal 1162. Medieval Encounters, 21, 81-120.

Martínez Gázquez, J. y Petrus, N. (2008). Las motivaciones generales de las traducciones medievales latinas del Corán. The Journal of Medieval Latin, 18, 230-246.

Melo Carrasco, D. (2019). Lutero y el Corán: una traducción del prefacio latino de Lutero al Corán de Bibliander (1542). En M. Cordero y J. Cid (eds.), Contrarreforma católica, implicancias sociales y culturales: miradas interdisciplinarias (pp. 141-154). Santiago: Cuarto Propio.

Miller, G. (2013). Theodor Bibliander's Machumetis saracenorum principis eiusque successorum vitae, doctrina ac ipse alcoran (1543) as the Sixteenth-century "Encyclopedia" of Islam. Islam and Christian-Muslim Relations, 24(2), 241-254.

Petrus, N. (2004). La Llegenda de Mahoma a 1' Edad Mitjana i al Renaixement: la vida del profeta. Revista de la Facultat de Lletres de la Universitat de Girona, 23-24, 161172.

Ramírez, E. (2014). Sola Fides, Sola Scriptura: la disputa de Leipzig y el rompimiento de Martín Lutero con la Iglesia Romana (1517-1521). En-Claves del Pensamiento, 8(15), 147-170.

Sandoval Martínez, S. (2006). La figura de Mahoma en Contra Perfidiam Mahometi, de Dionisio Cartujano. Antigüedad y Cristianismo, 23, 627-645. 
Sanz Santacruz, V. (2007). Juan de Segovia y Nicolás de Cusa frente al Islam: su comprensión intelectualista de la fe cristiana. Anuario de Historia de la Iglesia, 16, 181-194.

Schwoebel, R. H. (1965). Coexistence, conversion, and the crusade against the turks. Studies in the Renaissance, 12, 164-187.

Sénac, Ph. (2011). El occidente medieval frente al Islam: la imagen del otro. Granada: Universidad de Granada.

Simon, G. (1931). Luther's attitude towards Islam. The Muslim World, 21(3), 257-262.

Suárez, T. (2003). El sentido histórico del proyecto educativo de Lutero. Frónesis, 10(3), 956.

Tolan, J. (1996). Anti-Hagiography: Embrico of Mainz's Vita Mahumeti. Journal of Medieval History, 22(1), 25-41.

Tolan, J. (2007). Sarracenos. Valencia: Universitat de Valencia.

Tolan, J. (2010). Cribratio Alchorani. En D. Thomas (ed.), Christian-Muslim Relations 6001500. [Consultado el 18 de abril de 2017]. Recuperado de: http://dx.doi.org/10.1163/1877-8054_cmri_COM_25920

Valero Cuadra, P. (2000). Lutero y el Islam en tiempos de Carlos V. Carlos V. Los moriscos y el Islam. Alicante: Universidad de Alicante.

Wolf, C. U. (1941). Luther and mohammedanism. The Muslim World, 31(2), 161-177.

Cómo citar este artículo

Melo, D. (2020). "Martín Lutero y prefacio del Corán de Bibliander (1543)". Revista Cultura \& Religión,

$14(1), 26-40$ 